\title{
Natural Corrosion Inhibition and Adsorption Characteristics of Tribulus terrestris Plant Extract on Aluminium in Hydrochloric Acid Environment
}

\author{
Suchitra Chaudhary ${ }^{1, *(D)}$, Rakesh K. Tak ${ }^{2}$ (D) \\ Department of Chemistry, SPC Government College, Ajmer (Rajasthan), India \\ 2 Department of Chemistry, SPCGCA, MDS University, Ajmer (Rajasthan), India \\ * Correspondence: suchitra_gca@yahoo.com;
}

Scopus Author ID 57194602277

Received: 2.05.2021; Revised: 2.06.2021; Accepted: 5.06.2021; Published: 24.06.2021

\begin{abstract}
Corrosion inhibitive and adsorption capabilities of Tribulus terrestris plant extract on aluminum in $1.0 \mathrm{~N} \mathrm{HCl}$ solution was evaluated by mass loss and electrochemical methods. The inhibition efficiency increased with increasing extract concentration, whereas it decreased with increasing immersion time. The adsorption of the extract on the metal surface was physisorption, supported by $\Delta G_{\text {ads }}$ values( around $-20 \mathrm{~kJ} \mathrm{~mol}^{-1}$ ) and obeyed by Langmuir, Temkin and Freundlich adsorption isotherms. Electrochemical studies revealed mechanistic aspects of corrosion inhibition like Potentiodynamic polarization measurements indicated the nature of inhibitor is a mixed type and impedance studies supported the formation of a protective layer of inhibitor on a metal surface. SEM micrograms were also applied to study surface morphology. These images confirmed the creation of a protective film over the metal surface.
\end{abstract}

Keywords: corrosion; inhibition efficiency; Tribulus terrestris; Langmuir, Temkin and Freundlich adsorption isotherms; mass loss method and electrochemical method.

(C) 2021 by the authors. This article is an open-access article distributed under the terms and conditions of the Creative Commons Attribution (CC BY) license (https://creativecommons.org/licenses/by/4.0/).

\section{Introduction}

Aluminum metal is soft, durable, lightweight, low density $2.73 \mathrm{~g} / \mathrm{cm}^{3}$ and malleable [1]. It is non-magnetic, non-toxic and non-sparking, silvery-white metal. Aluminum has good thermal and electrical conductivity and is capable of being a superconductor at a critical temperature of $1.2 \mathrm{~K}$ and a magnetic field of about 100 gausses. Aluminum is the most abundant metal in the Earth's crust ( $8.3 \%$ by mass) and the third most common chemical element on our planet (after oxygen and silicon) [2]. It is the most commonly used nonferrous metal for fabrication purposes. Aluminum has several advantages over iron, such as abundance, lightweight, durability and resistance to corrosion.

Corrosion of metal is a major industrial problem and to control it, different methods reported in the literature are not only expensive but also toxic. The use of corrosion inhibitors is one of the best-known and most useful methods to protect materials from corrosion in the industry. Unfortunately, many of the inhibitors used are inorganic salts or organic compounds with limited solubility and toxic properties. Due to great awareness of health and environmental risks, our attention was redirected to find more suitable inhibitors which are non-toxic and ecofriendly. Therefore, a great need to investigate a non-toxic replacement as a green corrosion 
inhibitor compatible with current industrial technologies and the environment with their availability and relatively economical natural substances.

Organic compounds containing heterocyclic atoms of higher basicity and higher electron density, in addition to polar groups and $\pi$-electrons, have proven to be quite efficient in minimizing the influence of corrosion $[3,4]$.

These inhibitors generally have heteroatoms $\mathrm{O}, \mathrm{N}, \mathrm{S}$ and $\mathrm{P}$, which are the active centers for the adsorption process on the metal surface [5]. The inhibition efficiency for all these heteroatoms should follow the sequence $\mathrm{O}<\mathrm{N}<\mathrm{S}<\mathrm{P}$. The lone pair of electron and $\pi$ electrons of the inhibitor molecule accelerates electron transfer from inhibitor to metal. In general, organic compounds such as acetylenic alcohol, amines, thiols, tannins, flavonoids, steroids, saponins, and other nitrogen-containing heterocyclic compounds have been used as inhibitor.

Many investigations have been done to work out on the use of natural plant extracts as corrosion inhibitors for Aluminium in $\mathrm{HCl}$ medium such as Azadirachia Indica (AZI) [6], Lawsonia inermis [7], Andrographis panniculata [8] Areca flower extract [9] Cyamopsis tetragonolobus (Guar gum) [10] Newbouldia laevis leaves [11] extracts of Borassus flabellifer dust [12].

In the present study, plant Tribulus terrestris has been selected to investigate its anticorrosion behavior for aluminum in an acidic medium $(\mathrm{HCl})$. This plant possesses various pharmacological properties and has been traditionally used in folk medicines. The alcoholic extract of various aerial parts (Fruit, Leaf and Stem) of this plant has been used in different concentrations as corrosion inhibitors.

The genus Tribulus of the Zygophyllaceae family comprises 25 genera and about 250 species in the world [13], of which 3 species, viz Tribulus terrestris, Tribulus alatus and Tribulus cistoides, are commonly found in India. Among them, Tribulus terrestris is mainly used by modern herbalists as well as by Ayurvedic seers as a medicinal herb [14]. The previous phytochemical study of Tribulus terrestris [15] has reported the presence of saponins, glycosides, flavonoids, tannins and alkaloids. It was also found that the methanolic extract of this plant has more phytochemical compounds than aqueous extract[16].

The use of the Tribulus terrestris has been reported to inhibit the corrosion of mild steel in $\mathrm{H}_{2} \mathrm{SO}_{4}$ solutions [17] in phosphoric acid [18] and aluminum in Basic Media [19].

\section{Materials and Methods}

\subsection{Test coupons and solutions.}

The clean abraded, washed and dried rectangular aluminum coupons of Gauge 25 $(0.045 \mathrm{~cm})$, density $2.70\left(\mathrm{gm} / \mathrm{cm}^{3}\right)$ with dimension $2.5 \mathrm{~cm} \times 3.0 \mathrm{~cm} \times 0.045 \mathrm{~cm}$ containing a small hole of about $3 \mathrm{~mm}$ diameter near the upper edge were used for the experiment.

The solution of $1.0 \mathrm{~N} \mathrm{HCl}$ was prepared by dilution of analytical reagent grade $\mathrm{HCl}$ with bi-distilled water. The extracts were prepared by drying the fruit, leaf and stem part of the plants in air, then finely powdered and extracted by boiling with $80 \%$ methanol in the Soxhlet apparatus. The concentration range of various extracts of a plant used was $0.12 \%-0.60 \%$.

\subsection{Mass loss measurements.}

The coupons of aluminum were immersed in $50 \mathrm{ml}$ of $1.0 \mathrm{~N} \mathrm{HCl}$ solutions for predefined time with and without plant extract at $303 \pm 1 \mathrm{~K}$ temperature. All coupons were washed with double distilled water, dried, weighed and mass loss of coupons was measured for 
a workout of the influence of various parameters, such as concentration of inhibitor and time. The mass of coupons was measured using a weighing machine of precision of $\pm 0.1 \mathrm{mg}$. The Inhibition Efficiency (IE\%), degree of surface coverage $(\theta)$ and corrosion rate were calculated [20] by Equation (1).

$$
\mathrm{IE} \%=\left(1-\frac{\Delta \mathrm{M}}{\Delta \mathrm{M}_{0}}\right) 100
$$

where, $\Delta \mathrm{M}_{0}$ is mass loss of metal without inhibited acid and $\Delta \mathrm{M}$ is mass loss of metal with inhibited acid.

The Corrosion Rate (CR) can be obtained [21] by Equation (2).

$$
\mathrm{CR}=\frac{8.76 \times 10^{4} \times \Delta \mathrm{M}}{\mathrm{A} \times \mathrm{T} \times \mathrm{D}}
$$

where, CR is in millimeter per year (mmpy), mass loss is in gram, the area is expressed in $\mathrm{cm}^{2}$, time in hours and density is expressed in $\mathrm{gram} / \mathrm{cm}^{3}$.

\subsection{Electrochemical measurements.}

The electrochemical studies were made using a Gamry Potentiostat/Galvanostat (Model Reference 600) with EIS software Gamry Instruments Inc., USA. The cell body consists of 250 $\mathrm{mL}$ flat-bottom five-necked glass flask with three-electrode cell assemblies (Euro cellTM) connected to a computer-controlled potentiostat. The cell assembly consists of following electrodes (i) working electrode - aluminium coupon of $15 \mathrm{~cm}^{2}$ (ii) Auxiliary/ Counter electrode - graphite electrode and (iii) Reference electrode - Standard Calomel Electrode (SCE).

All the measurements for Potentiodynamic polarization studies were done by changing the electrode potential automatically from -0.10 to $0.10 \mathrm{~V}$ vs. reference electrode to determine the corrosion current $\left(\mathrm{I}_{\text {corr }}\right)$. The impedance measurement was carried out at open circuit potential under unstirred conditions and a stabilization period of $30 \mathrm{~min}$ for the frequency range from $100 \mathrm{kHz}$ to $100 \mathrm{mHz}$.

$\mathrm{IE} \%=\left(\frac{\mathrm{I}_{\text {corr }}^{0}-\mathrm{I}_{\text {corr }}}{\mathrm{I}_{\text {corr }}^{0}}\right) 100$

where, $\mathrm{I}_{\text {corr }}^{0}$ and $\mathrm{I}_{\text {corr }}$ are the corrosion current in absence and in presence of inhibitor, respectively.

For electrochemical impedance studies, electrochemical parameters such as charge transfer resistance $\left(\mathrm{R}_{\mathrm{ct}}\right)$ and double layer capacitance were determined from impedance data. The inhibition efficiency is calculated from the $R_{c t}$ value by using [22]:

$\mathrm{IE} \%=\left(\frac{\mathrm{R}_{\mathrm{ct}-} \mathrm{R}_{\mathrm{ct}}^{0}}{\mathrm{R}_{\mathrm{ct}}}\right) 100$

where, $R^{0}$ ct and $R_{c t}$ are the charge transfer resistance in the absence and in the presence of inhibitor, respectively. 


\section{Results and Discussion}

\subsection{Mass loss measurements.}

The gravimetric parameters and their calculation for corrosion rate, surface coverage and inhibition efficiency are obtained from the mass loss method for the following two parameters at $303 \pm 1 \mathrm{~K}$.

\subsubsection{Inhibitor concentration.}

Here it is studied the corrosion inhibitive properties of various extracts of plant Tribulus terrestris as organic and natural inhibitor for corrosion inhibition of aluminium in acidic medium. The effect of the inhibitor on the corrosion behavior of aluminum in hydrochloric acid is represented in Table 1. It is observed that the corrosion rate of $\mathrm{Al}$ in $\mathrm{HCl}$ containing inhibitor decreases with the increase of inhibitor concentration and inhibition efficiency increases with an increase in inhibitor concentration for plant extract from $0.12 \%$ to $0.60 \%$. The results revealed that the increase in inhibition efficiency may be because the inhibition action takes place via adsorption of organic molecules present in the inhibitor onto the aluminium surface [23].

It is presumed that the corrosion reactions are nullified from the active sites of a metal surface by covering its adsorbed inhibitor species, whereas the corrosion reactions usually take place on the inhibitor-free area. Therefore, the inhibition efficiency is directly proportional to the fraction of the surface covered with adsorbed substances [24].

Table 1. Gravimetric parameters of aluminium in $1.0 \mathrm{~N} \mathrm{HCl}$ with various concentrations of inhibitor at $303 \pm 1 \mathrm{~K}$. The effective area of specimen - 15.0; Immersion Time - 30 minutes.

\begin{tabular}{|c|c|c|c|c|}
\hline $\begin{array}{l}\text { Concentration } \\
\text { of inhibitor } \\
\text { w/v }(\%)\end{array}$ & $\begin{array}{l}\text { Mass loss, } \Delta \mathbf{M} \\
\quad(\mathbf{m g})\end{array}$ & $\begin{array}{c}\text { Corrosion } \\
\text { Rate, CR } \\
(\mathbf{m m p y})\end{array}$ & $\begin{array}{c}\text { Surface } \\
\text { coverage, } \theta\end{array}$ & $\begin{array}{c}\text { Inhibition } \\
\text { Efficiency, IE } \\
(\%)\end{array}$ \\
\hline Blank & 453.7 & 1962.7 & & \\
\hline \multicolumn{5}{|c|}{ Fruit extract } \\
\hline 0.12 & 218.2 & 943.9 & 0.5191 & 51.91 \\
\hline 0.24 & 151.5 & 655.4 & 0.6661 & 66.61 \\
\hline 0.36 & 109.2 & 472.4 & 0.7593 & 75.93 \\
\hline 0.48 & 82.8 & 358.2 & 0.8175 & 81.75 \\
\hline 0.60 & 65.5 & 283.3 & 0.8556 & 85.56 \\
\hline \multicolumn{5}{|c|}{ Leaf extract } \\
\hline 0.12 & 222.6 & 963.0 & 0.5094 & 50.94 \\
\hline 0.24 & 171.4 & 741.5 & 0.6222 & 62.22 \\
\hline 0.36 & 133.7 & 578.4 & 0.7053 & 70.53 \\
\hline 0.48 & 100.5 & 434.8 & 0.7785 & 77.85 \\
\hline 0.60 & 79.3 & 343.0 & 0.8252 & 82.52 \\
\hline \multicolumn{5}{|c|}{ Stem extract } \\
\hline 0.12 & 234.1 & 1012.7 & 0.4840 & 48.40 \\
\hline 0.24 & 178.5 & 772.2 & 0.6066 & 60.66 \\
\hline 0.36 & 148.8 & 643.7 & 0.672 & 67.20 \\
\hline 0.48 & 124.2 & 537.3 & 0.7263 & 72.63 \\
\hline 0.60 & 89.9 & 388.9 & 0.8019 & 80.19 \\
\hline
\end{tabular}

\subsubsection{Immersion time.}

The obtained data of inhibition efficiency and corrosion rate for aluminum coupons at different time periods explains the effectiveness of inhibitor action of different parts of plant Tribulus terrestris throughout immersion time. Based on corrosion rate data in the blank, it is concluded that aluminum is corroded vigorously in hydrochloric acid medium. The values for corrosion rate obtained in the presence of inhibitor are much less than that of blank for all the 
immersion time indicates film's existence on the corroding surface. It is observed in Table 2 that IE decreases with increasing immersion time. Because as the period of immersion increases, the protective film of inhibitor molecules formed on the metal surface, the aggressive acid medium and IE decreases [25].

Table 2. Gravimetric parameters of aluminium in $1.0 \mathrm{~N} \mathrm{HCl}$ with various time intervals at $303 \pm 1 \mathrm{~K}$. Effective

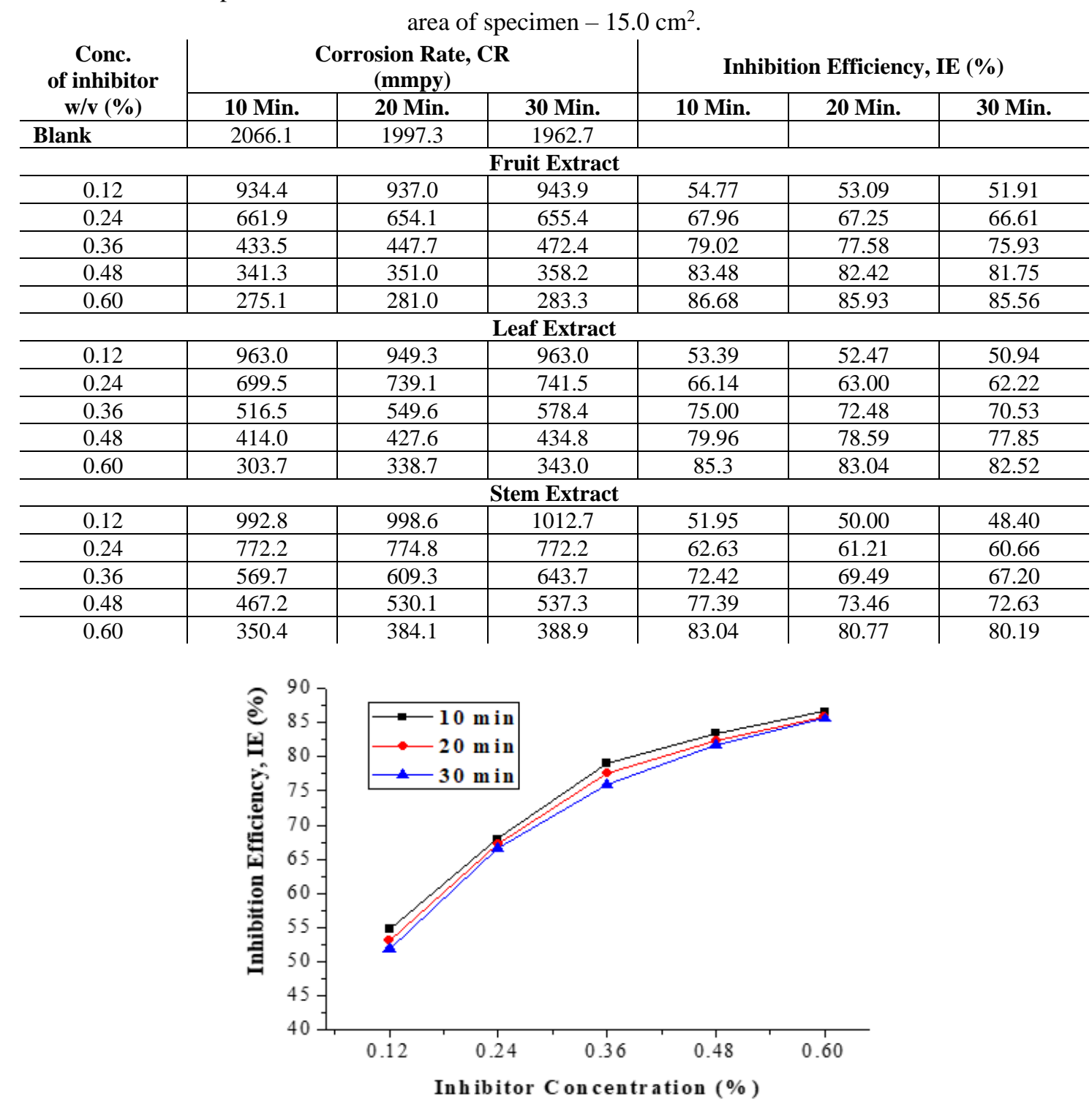

Figure 1. Effect of inhibitor concentration and immersion time on inhibition efficiency for fruit extract.

3.1.3. Applicability of adsorption isotherms.

To determine the mechanism of corrosion adsorption, different adsorption isotherm graphs were plotted. The gravimetric results have shown that the inhibition process occurs through an adsorption mechanism, where inhibitors form a thin protective film on the metal surface, which protects it from aggressive media. The efficiency of adsorbate (inhibitor molecule) directly depends on the surface covered $(\theta)$ by adsorbed molecule. The surface coverage of the inhibitor is calculated using the following equation in the mass loss method.

$$
\theta=\frac{M_{0}-M}{M_{0}}
$$


All the adsorption isotherms describe the relationship between surface coverage and extract concentration.

\subsubsection{Langmuir adsorption isotherm.}

The Langmuir adsorption isotherm equation is shown as:

$$
\log \left(\frac{\theta}{1-\theta}\right)=\log C+\log \mathrm{K}_{\mathrm{ads}}
$$

where, $\mathrm{C}$ is a concentration of inhibitor, $\theta$ is a fraction of surface coverage area, $\mathrm{K}_{\mathrm{ads}}$ is adsorption equilibrium constant.

When a graph is plotted between $\log (\theta / 1-\theta)$ and $\log C$, a straight line $\left(\mathrm{R}_{2}>0.9\right)$ is obtained as shown in figure 2 with gradient (slope) equal to one and intercept equal to $\log \mathrm{K}_{\mathrm{ads}}$. The values of all linear correlation coefficients $(\mathrm{R})$ are almost near to 1, indicates the adsorption of plant extract on aluminum surface obeys Langmuir adsorption isotherm. Langmuir isotherm indicates monolayer adsorption of inhibitor molecule, or we can say inhibitor molecule occupies one active site on a metal surface. However, the gradient is practically not unity because there is an assumption in Langmuir isotherm that there is no interaction between adsorbed molecules and between adsorbate and adsorbent molecules. This condition is not practically possible; therefore, the gradient is not unity [26]. Langmuir adsorption isotherm indicated that the organic components present in the plant extracts having polar atom or groups are adsorbed on the metal surface may interact by mutual repulsion or attraction $[27,28]$.

The reciprocal intercept values of Langmuir plots are equal to the adsorption equilibrium constant $\left(\mathrm{K}_{\mathrm{ads}}\right)$ represents the degree of adsorption. The $\mathrm{K}_{\mathrm{ads}}$ values are used to calculate free the energy of adsorption ( $\Delta \mathrm{G}_{\text {ads }}^{0}$ ).

\subsubsection{Temkin adsorption isotherm.}

The Temkin adsorption isotherm equation shown as

$$
\begin{aligned}
& \mathrm{e}^{-2 \mathrm{a} \theta}=\mathrm{K}_{\mathrm{ads}} \mathrm{C} \\
& \theta=\frac{-2.303 \log K a d s}{2 a}+\frac{-2.303 \log C}{2 a}
\end{aligned}
$$

where, $\mathrm{C}$ is a concentration of inhibitor, $\theta$ is a fraction of surface coverage area, $\mathrm{K}_{\mathrm{ads}}$ is adsorption equilibrium constant.

When the graph is plotted between $\theta$ and $\log \mathrm{C}$, a straight line is obtained (figure 2), the plot supports the proclamation that the mechanism of corrosion inhibition is due to the formation of a protective film on the metal surface. The fit of the experimental data to these isotherms provides evidence for the role of adsorption in the observed inhibitive effect of Tribulus terristris. From Temkin data observed that the corrosion inhibition by inhibitor compounds is a result of their adsorption on the metal surface [29]. The attractive parameter (a) 's negative values (a) indicate that repulsion exists in the adsorption layer [30].

\subsubsection{Freundlich isotherm.}

The Freundlich isotherm is given by the equation shown as 
$\log \theta=\log \mathrm{K}_{\mathrm{ads}}+\frac{1}{n} \log \mathrm{C}$

where $\mathrm{n}$ is the interaction parameter.

The plot of $\log \theta$ vs. $\log C$ shown in figure 2 is linear and the linearity proves that the adsorption of inhibitor on aluminum surface follows Freundlich isotherm. The slope is the value of $1 / \mathrm{n}$ and the intercept is equal to $\log \mathrm{K}_{\mathrm{ads}}$. From the graph, the values of $\mathrm{K}_{\mathrm{ads}}$ and $\mathrm{n}$ are calculated. Value of $n$ is a measure of adsorption intensity or surface heterogeneity. If $n=0$, there is more surface heterogeneity, $n<1$ implies chemisorption whereas $n>1$ indicates cooperative adsorption [31].

The adsorption studies clearly revealed that the experimental data fitted the Langmuir, Freundlich and Temkin adsorption isotherm with a correlation coefficient greater than 0.90 . The adsorption equilibrium constant (Kads) value in $(\mathrm{g} / \mathrm{L})$ is highest for fruit extract and lowest for stem extract in all adsorption isotherm, which indicates that fruit extract is the most effective inhibitor followed by leaf and stem extract aluminum surface. The value of $\Delta \mathrm{G}_{\text {ads }}^{0}$ is calculated with the help of the following equation:

$$
\Delta \mathrm{G}_{\mathrm{ads}}^{0}=-\mathrm{RT} \ln \left(55.5 \mathrm{~K}_{\mathrm{ads}}\right)
$$

where, $\Delta \mathrm{G}_{\text {ads }}^{0}$ is a change in Gibbs free energy, $\mathrm{K}_{\mathrm{ads}}$ is adsorption equilibrium constant, $\mathrm{R}$ is universal gas constant $\left(8.314 \mathrm{~J} \mathrm{~K}^{-1} \mathrm{~mol}^{-1}\right)$, $\mathrm{T}$ is absolute temp and 55.5 is a concentration of water (mol/litre).

The negative values of $\Delta \mathrm{G}_{\text {ads }}^{0}$ reveals that adsorption of inhibitor molecules on mild steel surfaces is a spontaneous process [32]. The value of $\Delta G_{\text {ads }}^{0}$ around $-20 \mathrm{~kJ} / \mathrm{mol}$ or lower supports the electrostatic interaction (physisorption) between the adsorbent and adsorbate [33]. From the values of affinity constants in Freundlich isotherm and adsorption capacity in all three isotherms, it was found that the fruit extract was most effective for adsorbing, followed by the leaf and stem, respectively.

Table 3. Adsorption parameters on aluminium corrosion inhibition by Tribulus terrestris plant extract obtained from Langmuir, Temkin and Freundlich adsorption isotherms.

\begin{tabular}{c|c|c|c|c|c|c|c} 
Extract & $\mathbf{R}^{\mathbf{2}}$ & Intercept & Slope & $\mathbf{a}$ & $\mathbf{n}$ & $\mathbf{K}$ & $\Delta$ Gads \\
\hline & & & Langmuir & & & & \\
\hline Fruit & 0.9864 & 1.038 & 1.065 & - & - & 10.93 & -16.14 \\
\hline Leaf & 0.9771 & 0.935 & 0.983 & - & - & 8.60 & -15.54 \\
\hline Stem & 0.9656 & 0.846 & 0.921 & - & - & 7.01 & -15.02 \\
\hline & & & Temkin & & & & \\
\hline Fruit & 0.9896 & 0.982 & 0.471 & -2.44 & - & 121.45 & -22.21 \\
\hline Leaf & 0.9979 & 0.949 & 0.454 & -2.53 & - & 122.80 & -22.24 \\
\hline Stem & 0.9888 & 0.920 & 0.445 & -2.59 & - & 116.34 & -22.10 \\
\hline & & & Freundlich & & & & \\
\hline Fruit & 0.9828 & 0.0140 & 0.2939 & - & 3.40 & 1.033 & -10.20 \\
\hline Leaf & 0.9966 & -0.0017 & 0.2908 & - & 3.44 & 0.996 & -10.11 \\
\hline Stem & 0.9963 & -0.0157 & 0.2935 & - & 3.41 & 0.964 & -10.03
\end{tabular}

\subsection{Electrochemical measurement.}

3.2.1. Potentiodynamic polarization measurements.

The electrochemical corrosion kinetic parameters were examined by using Gamry potentiostat/galvanostat. The anticorrosion behavior of inhibition was studied via anodic and 
cathodic polarization by plotting a curve between corrosion current density ( $\mathrm{I}_{\text {corr }}$ ) and corrosion potential $\left(\mathrm{E}_{\text {corr }}\right)$. These curves are known as the Tafel plot and the slope of the anodic and cathodic Tafel curves are $\beta_{\mathrm{a}}$ and $\beta_{\mathrm{c}}(\mathrm{mv} / \mathrm{dec}$ de), respectively.
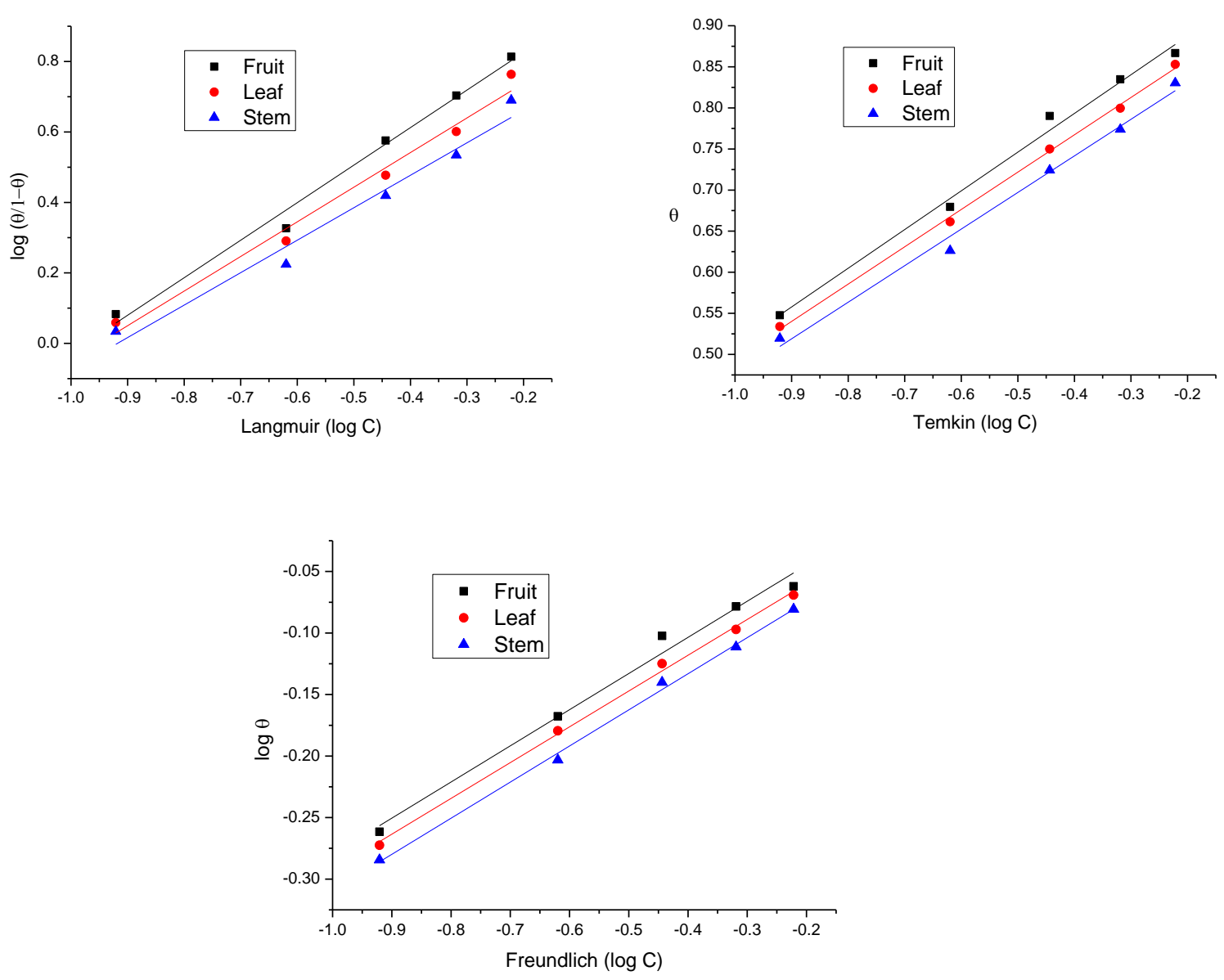

Figure 2. (a) Langmuir; (b) Temkin; (c) Freundlich isotherms for the adsorption of Tt extract on the surface of the aluminum in $1.0 \mathrm{~N} \mathrm{HCl}$.

The experimental data are shown in Table 4 and their computed Tafel plots are shown in figure 3. It can be seen from the experimental values that the corrosion current density decreases significantly with an increase in inhibitor concentration supports the retardation of the corrosion process [34].

The lower current density in the presence of inhibitor indicates that the metal surface is passivated due to the formation of the inhibitor layer [35].

The shift in Ecorr value is positive/negative side $40 \mathrm{mV}$, and by literature survey, it was found that if a shift in corrosion potential is less than $\pm 85 \mathrm{mV}$ with respect to corrosion potential of the blank solution, inhibitor act as mixed-type inhibitor; hence these inhibitors are mixed type of inhibitor [36].

The above study results show that fruit extract of the plant has better inhibition property than stem and leaf extract.

Significant changes in both the values of $\beta_{\mathrm{a}}$ and $\beta_{\mathrm{c}}$ as compare to blank solutions also suggest that these inhibitors protect the corrosion process by adsorption of inhibitor molecules on both anodic and cathodic sites. It is also shown in Tafel plots that there is a clear shift in the cathodic and anodic part of curves with the addition of inhibitors. So it is known as a mixed type inhibitor. 
Table 4. Potentiodynamic polarization parameters of aluminium in $1.0 \mathrm{~N} \mathrm{HCl}$ with various concentrations of the

\begin{tabular}{|c|c|c|c|c|c|c|c|}
\hline $\begin{array}{l}\text { Concentration } \\
\text { of inhibitor } \\
\text { w/v }(\%)\end{array}$ & $\begin{array}{l}\text {-Ecorr } \\
(\mathrm{mV})\end{array}$ & $\begin{array}{l}\text { icorr } \\
(\mu \mathrm{A} / \mathrm{cm} 2)\end{array}$ & $\begin{array}{l}\text { 及a } \\
\text { (mV/dec) }\end{array}$ & $\begin{array}{l}-\beta c \\
(\mathrm{mV} / \mathrm{dec})\end{array}$ & $\begin{array}{l}\text { CR } \\
\text { (mmpy) }\end{array}$ & $\boldsymbol{\theta}$ & $\begin{array}{l}\text { IE } \\
(\%)\end{array}$ \\
\hline Blank & 847 & 3620 & 108.5 & 6058.0 & 39.530 & - & - \\
\hline \multicolumn{8}{|c|}{ Fruit extract } \\
\hline 0.12 & 836 & 1650 & 72.7 & 851.4 & 17.960 & 0.5442 & 54.42 \\
\hline 0.36 & 840 & 720 & 55.8 & 567.7 & 7.855 & 0.8011 & 80.11 \\
\hline 0.60 & 844 & 520 & 40.8 & 580.8 & 5.673 & 0.8564 & 85.64 \\
\hline \multicolumn{8}{|c|}{ Leaf extract } \\
\hline 0.12 & 835 & 1702 & 84.7 & 320.7 & 18.580 & 0.5299 & 52.99 \\
\hline 0.36 & 847 & 952 & 62.6 & 360.5 & 10.380 & 0.7370 & 73.70 \\
\hline 0.60 & 842 & 569 & 59.8 & 6871.0 & 6.209 & 0.8428 & 84.28 \\
\hline \multicolumn{8}{|c|}{ Stem extract } \\
\hline 0.12 & 835 & 1826 & 81.9 & 3853.0 & 19.890 & 0.4956 & 49.56 \\
\hline 0.36 & 836 & 1060 & 77.2 & 561.4 & 11.600 & 0.7072 & 70.72 \\
\hline 0.60 & 828 & 732 & 74.8 & 3236.0 & 7.980 & 0.7978 & 79.78 \\
\hline
\end{tabular}

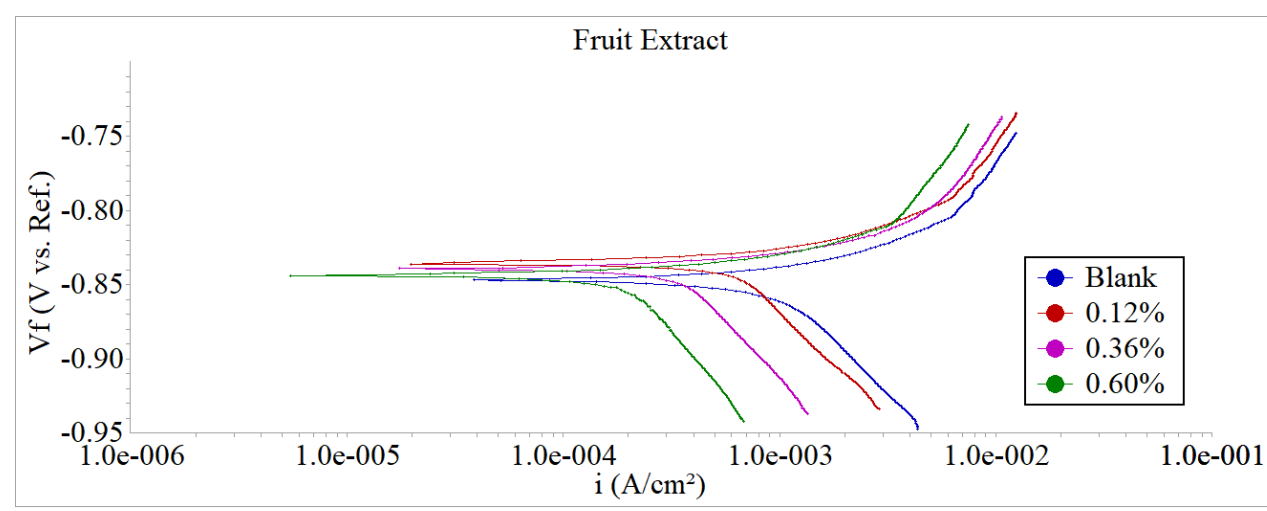

(a)

Leaf Extract

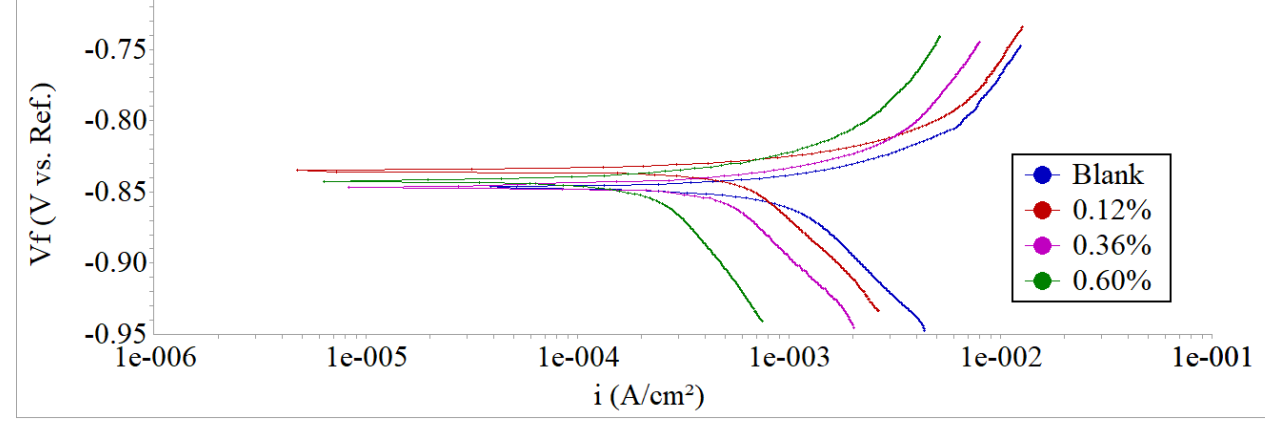

(b)

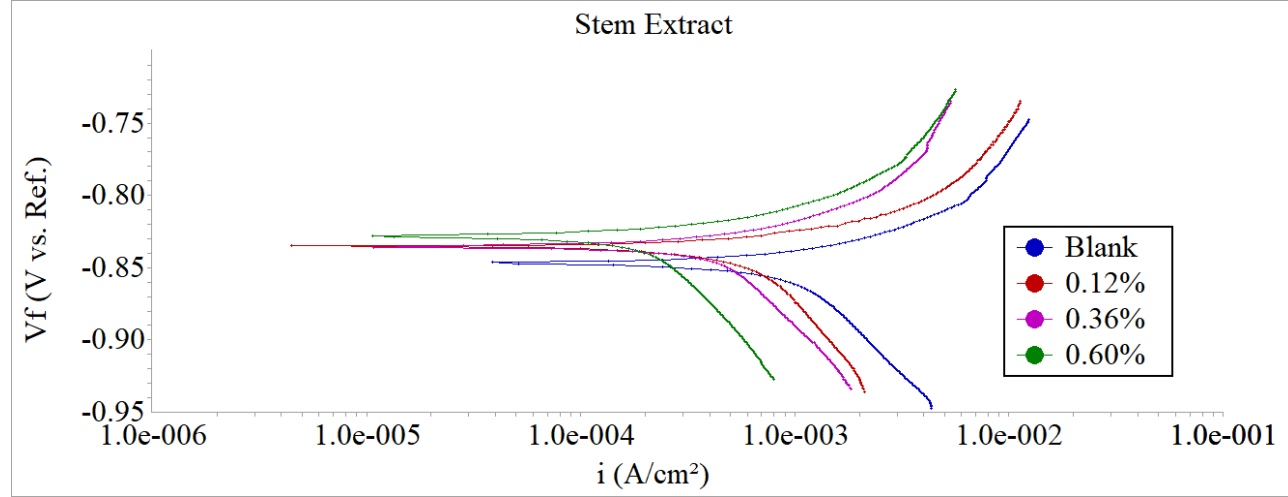

(c)

Figure 3. Tafel curve for aluminum in the absence and in the presence of different concentrations of Tribulus terrestris in $1.0 \mathrm{~N} \mathrm{HCl}$ (a) Fruit Extract; (b) Leaf Extract; (c) Stem. 


\subsubsection{Electrochemical impedance spectroscopy.}

The electrochemical impedance of a material is the most important property for studying the mechanism of inhibitor action on metals. Gamry Potentiostat/Galvanostat of frequency range from $100 \mathrm{kHz}$ to $100 \mathrm{mHz}$ was used to obtain electrochemical impedance data at open circuit potential.

The impedance behavior of aluminum in $\mathrm{HCl}$ with and without the addition of different plant extracts are presented as complex impedance plots (Nyquist plots) as well as Bode plots. The impedance parameters namely charge transfer resistance $\left(\mathrm{R}_{\mathrm{ct}}\right)$, double layer capacitance $\left(\mathrm{C}_{\mathrm{dl}}\right)$, solution resistance $\left(\mathrm{R}_{\mathrm{s}}\right)$ for aluminum in different concentration of $\mathrm{HCl}$ are shown in Table 5 The general semi-circle shape of curves is almost maintained throughout all concentration range of inhibitor manifest that there is no change in corrosion mechanism occurred on the addition of plant extract [37]. All the impedance curves shown in figure 5(A) were analyzed by fitting equivalent Randle's circuit model represented in figure 4 . That is constituted of series solution resistance $\left(R_{s}\right)$ with the parallel combination of resistance $R_{c t}$ and capacitor $\mathrm{C}_{\mathrm{dl}}$.

The increase in plot radius with an increase in inhibitor concentration indicates the increase of impedance due to an increase in the number of inhibitive molecules and also indicates that the corrosion rate of aluminum decreases with increasing extract concentration [38]

The value of charge transfer resistance increases with the addition inhibitor due's with creation to the protective film on aluminum or solution interface and reduces the double layer capacitance and increases the thickness of electronic double-layer [39]. These semi-circles also indicate that IE\% increases with an increase in inhibitor concentrations. It is also observed that these are not perfect due to the inhomogeneity of the aluminum surface arising from surface roughness or interfacial phenomena [40].

Table 5. Impedance parameters obtained using Randle equivalent circuit for aluminium in $1.0 \mathrm{~N} \mathrm{HCl}$ with various inhibitor concentrations at $303 \pm 1 \mathrm{~K}$.

\begin{tabular}{|c|c|c|c|c|c|}
\hline $\begin{array}{c}\text { Concentration } \\
\text { of inhibitor } \\
\text { w/v }(\%) \\
\end{array}$ & $\begin{array}{c}\mathbf{R}_{\text {sol }} \\
\left(\Omega \cdot \mathbf{c m}^{2}\right)\end{array}$ & $\begin{array}{c}\mathbf{R}_{\mathrm{ct}} \\
\left(\mathbf{\Omega . c m ^ { 2 }}\right)\end{array}$ & $\begin{array}{c}C_{d l} \\
\left(\mu F \mathbf{c m}^{-2}\right)\end{array}$ & $\boldsymbol{\theta}$ & $\begin{array}{l}\text { IE } \\
(\%)\end{array}$ \\
\hline Blank & 7.956 & 19.51 & 8.221 & - & - \\
\hline \multicolumn{6}{|c|}{ Fruit extract } \\
\hline 0.12 & 0.735 & 41.03 & 12.530 & 0.5245 & 52.45 \\
\hline 0.36 & 7.038 & 88.01 & 4.974 & 0.7783 & 77.83 \\
\hline 0.60 & 2.399 & 130.00 & 11.790 & 0.8499 & 84.99 \\
\hline \multicolumn{6}{|c|}{ Leaf extract } \\
\hline 0.12 & 2.611 & 39.12 & 9.884 & 0.5013 & 50.13 \\
\hline 0.36 & 5.502 & 70.66 & 8.055 & 0.7239 & 72.39 \\
\hline 0.60 & 4.143 & 116.00 & 9.436 & 0.8318 & 83.18 \\
\hline \multicolumn{6}{|c|}{ Stem extract } \\
\hline 0.12 & 1.745 & 38.18 & 8.236 & 0.4890 & 48.90 \\
\hline 0.36 & 5.820 & 62.08 & 6.602 & 0.6857 & 68.57 \\
\hline 0.60 & 4.259 & 114.00 & 8.031 & 0.8289 & 82.89 \\
\hline
\end{tabular}

The prohibition of corrosion is again supported by the rise in the phase angle with the increase in the concentration of fruit, leaf, or stem extract of plant Tribulus terrestris, as shown in the Bode plot in figure 5(B) [41]. The value of phase angle in these plots is related to the roughness of the electrode surface. The higher the value of $\theta$ max lower is the surface roughness. 
Therefore on increasing inhibitor concentration, surface roughness decrease means corrosion decreased.

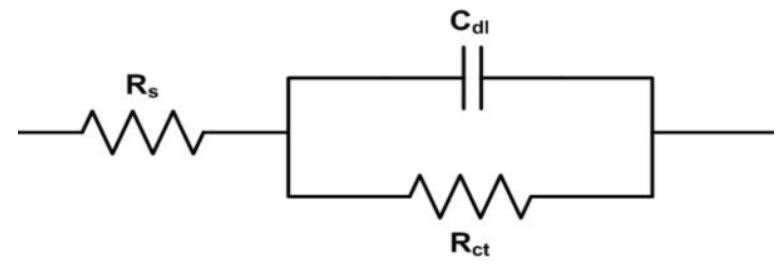

Figure 4. Randle equivalent circuits corresponding to the analyzed system.

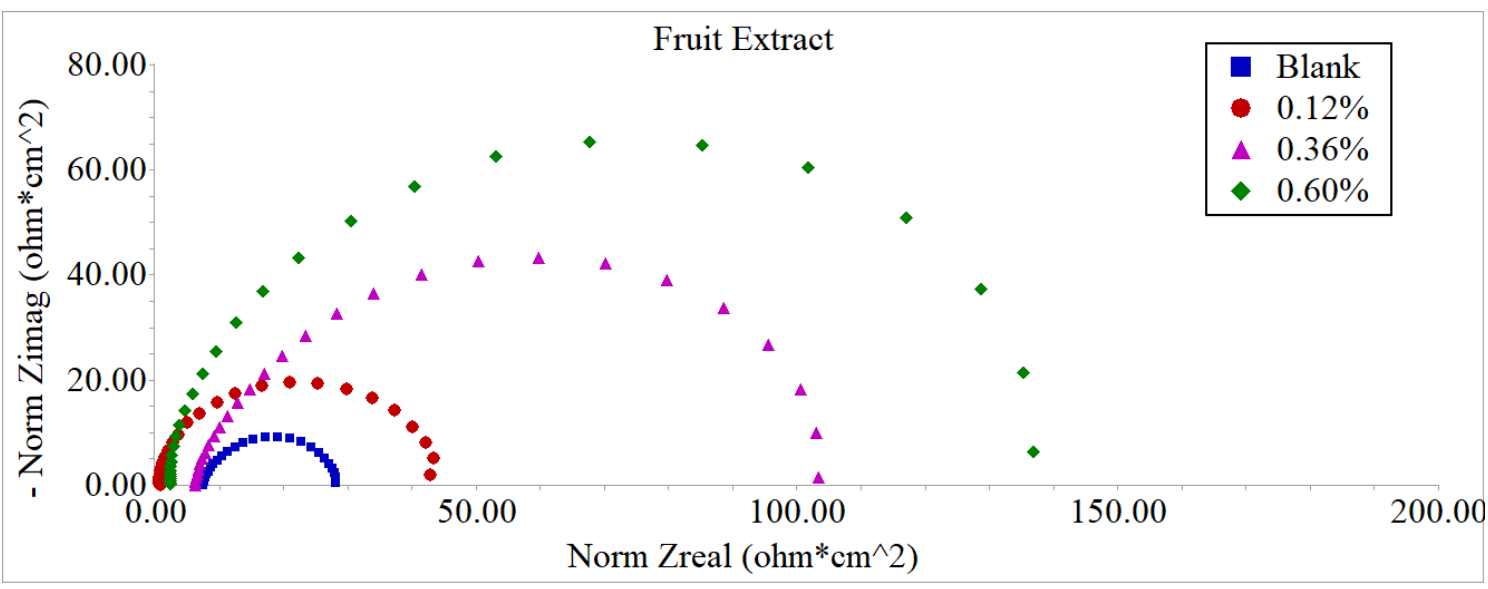

(a)

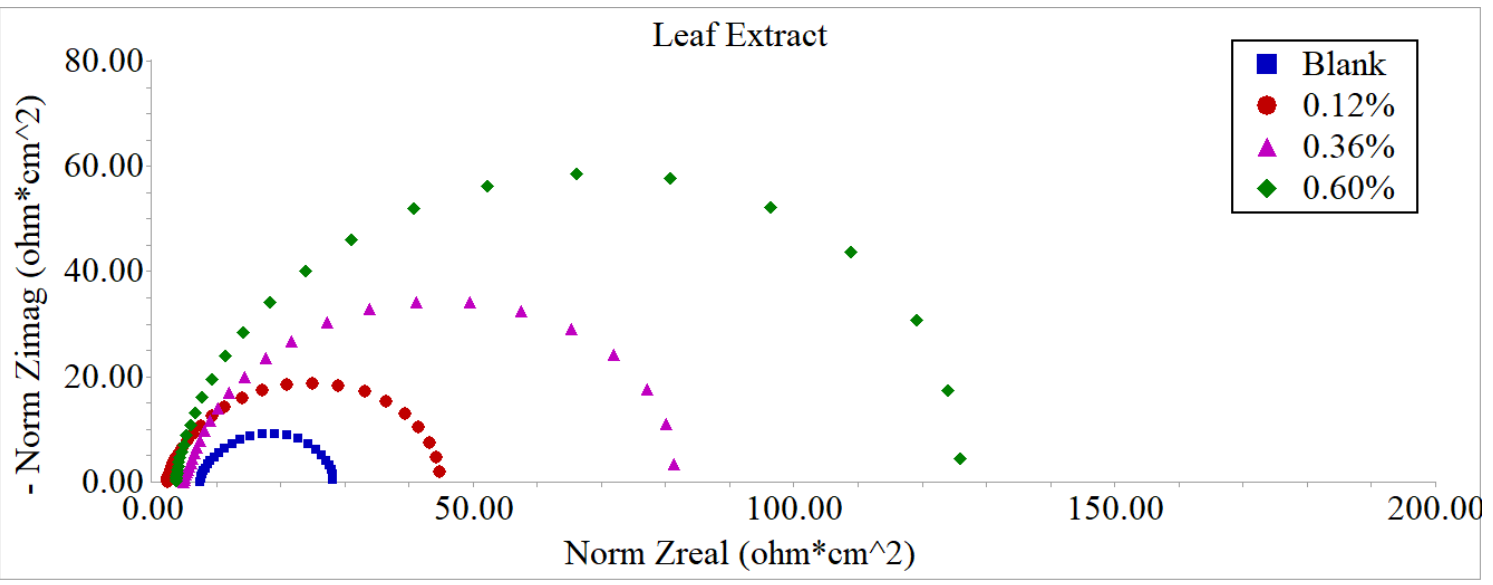

(b)

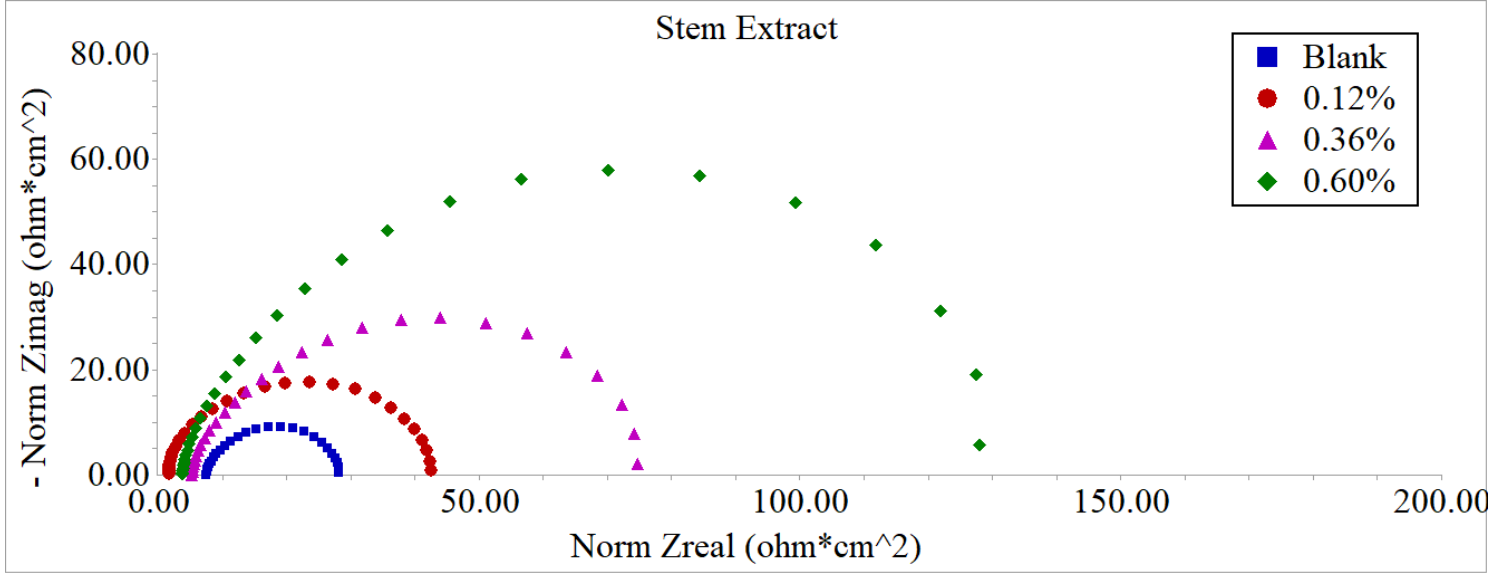

(c)

Figure 5(A). The nyquist curve for aluminum in different concentrations of Tribulus terrestris in $1.0 \mathrm{~N} \mathrm{HCl}(\mathbf{a})$ Fruit Extract; (b) Leaf Extract; (c) Stem Extract. 


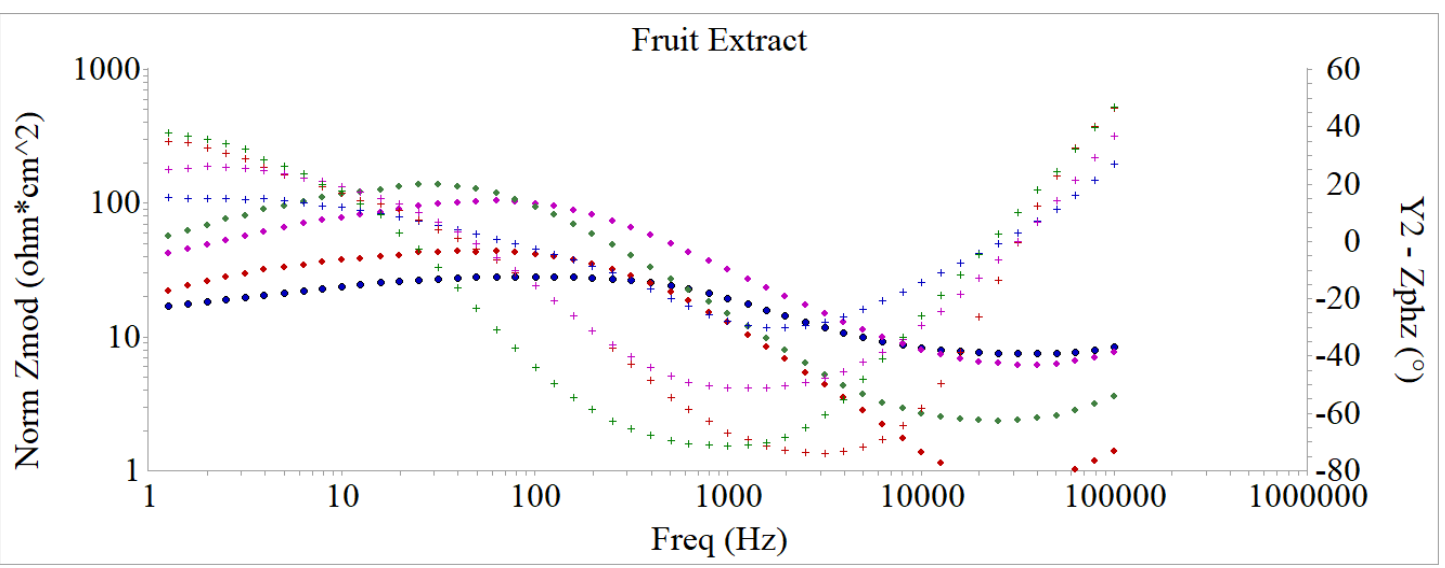

(a)

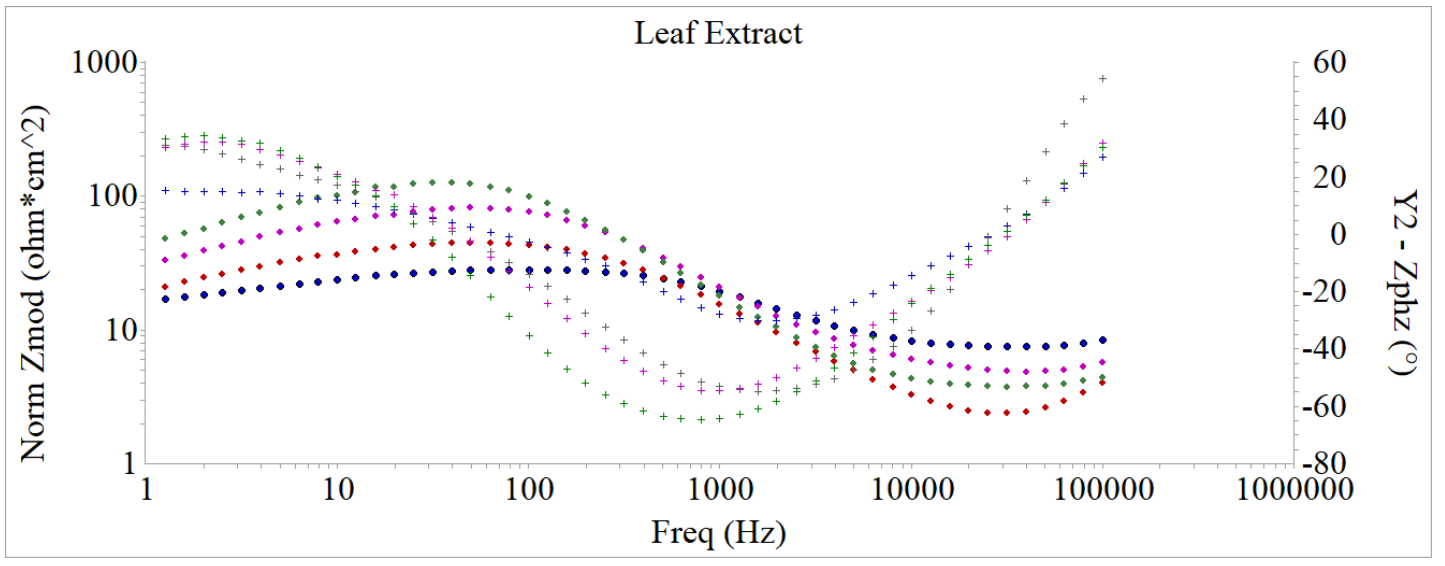

(b)

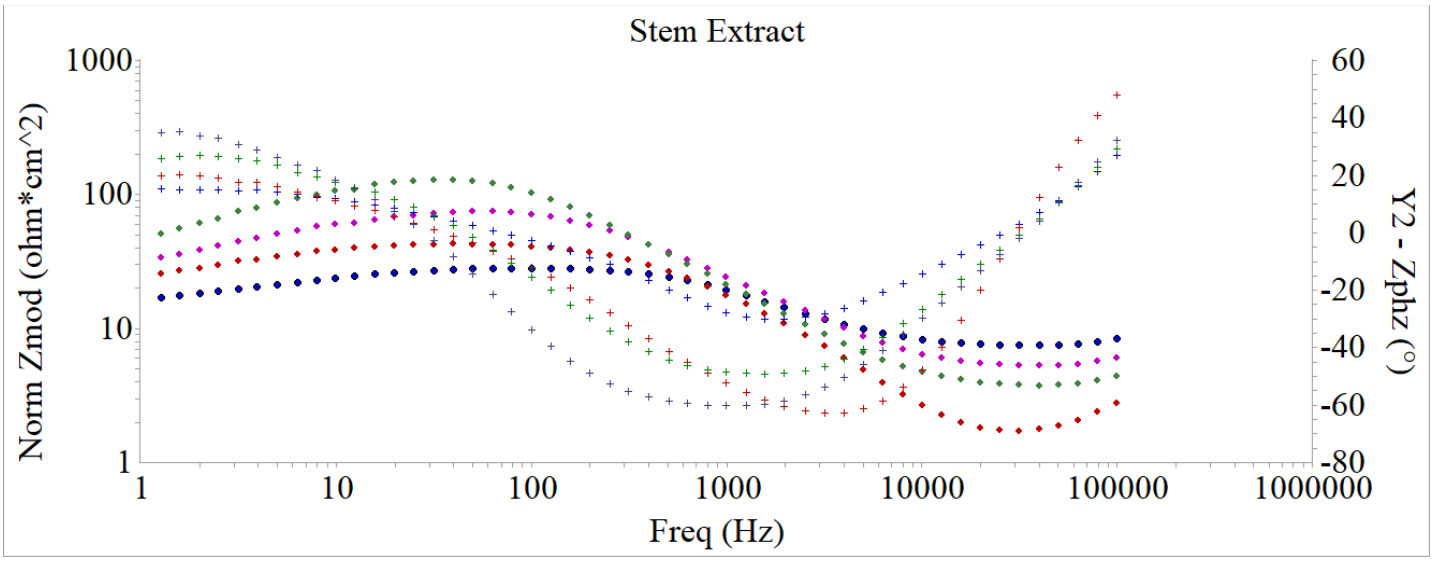

(c)

$\begin{array}{llll}\text { Blank } & -0.12 \% & -0.36 \% & -0.60 \% \\ \text { Y2 - Blank } & +\mathrm{Y} 2-0.12 \% & +\mathrm{Y} 2-0.36 \% & +\mathrm{Y} 2-0.60 \%\end{array}$

Figure 5 (B). Bode curve for aluminum in different concentrations of Tribulus terrestris in 1.0N HCl: (a) Fruit Extract; (b) Leaf Extract; (c) Stem Extract.

\subsection{SEM Analysis.}

The SEM micrographs of magnification (x10000) of aluminum were used for their surface analysis. The SEM images of aluminum specimens in untreated condition and after immersion in $1.0 \mathrm{~N} \mathrm{HCl}$ for 24 hours with and without $0.60 \%$ fruit extract of Tribulus terrestris are shown in figure 6 a,b,c, respectively. The SEM image of the untreated metal surface shows the smooth metal surface, which indicates the absence of any corrosion product on a metal surface. It can be clearly observed that the surface of aluminum in acidic media without inhibitor shows more roughness with pits and cracks because of badly attack by a corrosive 
environment with compare to those coupons which immersed in acidic media containing inhibitor. These observations reveal that Tribulus terrestris plant extract is able to reduce the corrosion rate in the acidic environment due to the formation of a film layer of an insoluble complex on the surface of the metal. The metal surface is covered with a thin layer of the inhibitor $[42,43]$.

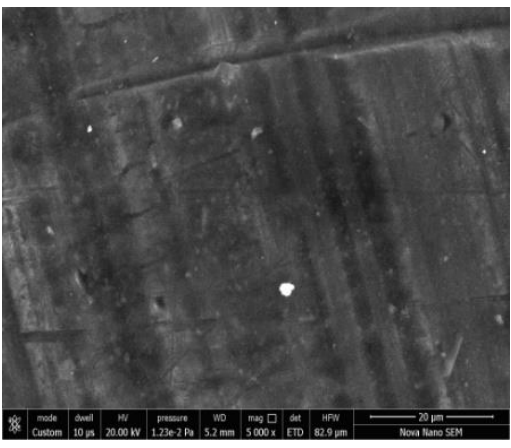

Al-Pure (a)

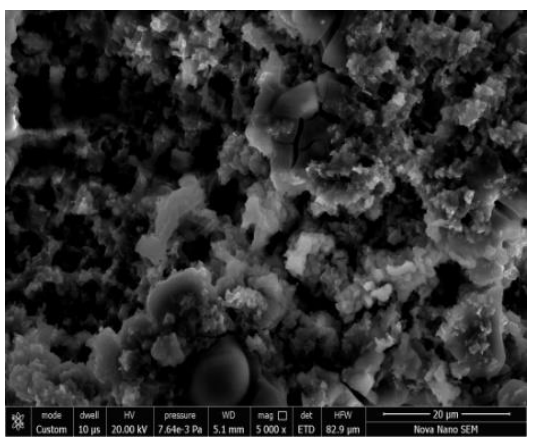

Al - Blank (b)

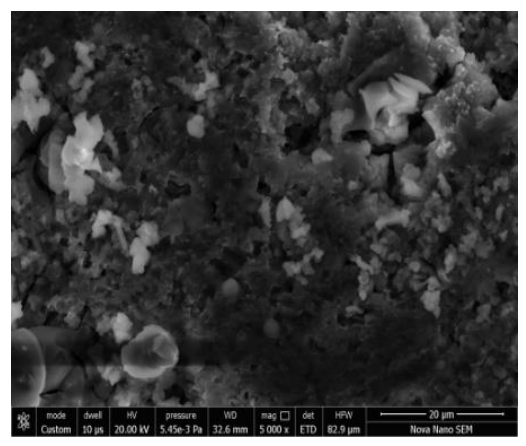

$\mathrm{Al}-0.60 \% \mathrm{~F}(\mathrm{c})$

Figure 6. SEM images of aluminium (a) untreated aluminium; (b) aluminium in $1.0 \mathrm{~N} \mathrm{HCl}$ (blank solution); (c) aluminium in $1.0 \mathrm{~N} \mathrm{HCl}$ with $0.60 \%$ fruit extract.

\section{Conclusions}

All the plant extract (i.e., fruit, leaf and stem) studied were found to be effective corrosion inhibitors for aluminum in hydrochloric acid medium. The results lead to the following conclusions:

Mass loss study results reveal that inhibition efficiency (IE\%) increases with inhibitor concentration decreases with increasing immersion time and maximum IE\% was observed for fruit extract at the concentration of $0.60 \%$ at $303 \mathrm{~K}$; The adsorption of different concentrations of the plant extract on the surface of the aluminium in $1.0 \mathrm{~N} \mathrm{HCl}$ solution follows Langmuir, Temkin and Freundlich adsorption isotherm; The EIS analysis indicates that the corrosion resistance or impedance increase with extract of Tribulus terrestris by the formation of a protective layer on metal; The Tafel analysis indicates that plant extract is a mixed-type inhibitor; The analysis of experimental values of mass loss, Tafel polarization and EIS are in good agreement with one another; These inhibitors were observed as economical, powerful as well as an eco-friendly and less toxic tool for prevention of corrosion in the environment of industrial area.

\section{Funding}

This research has no funding declared.

\section{Acknowledgments}

The authors are thankful to the Department of Chemistry, SPC Govt. College, Ajmer, for their administrative and technical support and the Department of Metallurgical and Materials, MNIT, Jaipur, for their help and encouragement.

\section{Conflicts of Interest}

The authors declare no conflict of interest. 


\section{References}

1. Bashir, S.; Lgaz, H.; Chung, I.M.; Kumar, A. Effective green corrosion inhibition of aluminum using analgin in acidic medium: an experimental and theoretical study. Chem. Eng. Commun. 2020, 208, 1121-1130, https://doi.org/10.1080/00986445.2020.1752680.

2. Xhanari, K.; Finšgar, M. Organic corrosion inhibitors for aluminium and its alloys in acid solutions: a review. RSC advances, 2016, 6, 62833-62857, https://doi.org/10.1039/C6RA11818F.

3. El Kacimi, Y.; Azaroual, M.A.; Touir, R.; Galai, M.; Alaoui, K.; Sfaira, M.; Ebn Touhami, M.; Kaya, S. Corrosion inhibition studies for mild steel in $5.0 \mathrm{M} \mathrm{HCl}$ by substituted phenyltetrazole. EuroMediterr J Environ Integr 2017, 2, 1, https://doi.org/10.1007/s41207-016-0011-8.

4. Iroha, N.B.; Akaranta, O. Experimental and surface morphological study of corrosion inhibition of N80 carbon steel in $\mathrm{HCl}$ stimulated acidizing solution using gum exudate from Terminalia Mentaly. SN Appl Sci 2020, 2, 1514, https://doi.org/10.1007/s42452-020-03296-8.

5. Zaher, A.; Chaouiki, A.; Salghi, R.; Boukhraz, A.; Bourkhiss, B.; Ouhssine, M. Inhibition of Mild Steel Corrosion in 1M Hydrochloric Medium by the Methanolic Extract of Ammi visnaga L. Lam Seeds. Int. J. Corros. 2020, 2020, https://doi.org/10.1155/2020/9764206.

6. Arab, S.T.; Al-Turkustani, A.M.; Al-Dhahiri, R.H. Synergistic effect of Azadirachta Indica extract and iodide ions on the corrosion inhibition of aluminium in acid media. J. Korean Chem. Soc. 2008, 52, 281-294, http://dx.doi.org/10.5012/jkcs.2008.52.3.281.

7. Petchiammal, A.; Selvaraj, S. The corrosion control of aluminium using Lawsonia inermis seed extract in acid medium. Int. J. Chemtech Res. 2013, 5, 1566-1574.

8. Pushpanjali, M.; Suma Rao. Inhibition study of Andrographis paniculata plants extract for the corrosion control Of Aluminium in hydrochloric acid medium. Int. J. Chemtech Res. 2017, 9, 291-304, http://eprints.manipal.edu/id/eprint/148321.

9. Raghavendra, N.; Bhat, J.I. Inhibition of Al corrosion in $0.5 \mathrm{M} \mathrm{HCl}$ solution by Areca flower extract. J. King Saud Univ. Eng. Sci. 2019, 1, 202-208, https://doi.org/10.1016/j.jksues.2017.06.003.

10. Palumbo, G.; Berent, K.; Proniewicz, E.; Banaś J. Guar gum as an eco-friendly corrosion inhibitor for pure aluminium in 1-M HCl solution. Mater 2019, 12, 2620, https://doi.org/10.3390/ma12162620.

11. Udensi, S.C.; Ekpe, O.E.; Nnanna, L.A. Newbouldia laevis leaves extract as tenable eco-friendly corrosion inhibitor for aluminium alloy AA7075-T7351 in $1 \mathrm{M}$ HCL corrosive environment: Gravimetric, electrochemical and thermodynamic studies. Chem. Afr. 2020, 3, 303-316, https://doi.org/10.1007/s42250020-00131-w.

12. Nathiya, R.S.; Perumal, S.; Murugesan, V.; Raj, V. Evaluation of extracts of Borassus flabellifer dust as green inhibitors for aluminium corrosion in acidic media. Mater. Sci. Semicond. Process 2019, 1, 104674, https://doi.org/10.1016/j.mssp.2019.104674.

13. Abdulqawi, L.N.; Quadri, S.A.; Evaluation of Antibacterial and Antioxidant activities of Tribulus terrestris L. Fruits. Research Journal of Pharmacy and Technology 2021, 14, 331, https://doi.org/10.5958/0974360X.2021.00061.5.

14. Duke, J.A.; Bogenschutz-Godwin, M.J.; Duke, P.A.K. 2nd edn. Duke Handbook of medicinal herbs. United States: CRC Press, 2002; 595, http://localhost:8080/xmlui/handle/123456789/73.

15. Ștefănescu, R.; Tero-Vescan, A.; Negroiu, A.; Aurică, E.; Vari, C.E. A Comprehensive Review of the Phytochemical, Pharmacological, and Toxicological Properties of Tribulus terrestris L. Biomolecules. 2020, 10, 5, 752, https://doi.org/10.3390/biom10050752.

16. Abdulqawi, L.N.A.; Quadri, S.A. Evaluation of Antibacterial and Antioxidant activities of Tribulus terrestris L. Fruits. Res J Pharm Technol 2021, 14, 331-336, https://doi.org/10.5958/0974-360X.2021.00061.5.

17. Chaudhary, S.; Tak, R.K.; Duchaniya, R.K. Corrosion Inhibition of Mild Steel in $0.5 \mathrm{~N} \mathrm{H}_{2} \mathrm{SO}_{4}$ Solution by Tribulus terrestris (Fruit) Extract. J. surf. sci. nanotechnol. 2017, 33, 63-69, https://doi.org/10.18311/jsst/2017/15575.

18. Sivaraju, M.; Kannan, K. Eco-friendly inhibitor (Tribulus terrestris L) for mild steel corrosion in $1 \mathrm{~N}$ phosphoric acid. Asian J. Chem. 2010, 22, 233-244.

19. Rathi, P.; Kumar, S. Anticorrosive Effect of Tribulus terrestris on Aluminium in Basic Media. Surf. Eng. Appl. Electrochem. 2019, 55, 4, 430-5, https://doi.org/10.3103/S1068375519040124.

20. Khudhair, Z.T.; Shihab, M.S. Study of Synergistic Effect of Some Pyrazole Derivatives as Corrosion Inhibitors for Mild Steel in $1 \mathrm{M} \mathrm{H}_{2} \mathrm{SO}_{4}$. Surf. Eng. Appl. Electrochem. 2020, 56, 601-609, https://doi.org/10.3103/S1068375520050142.

21. Jones, D.A. Principles and Prevention of Corrosion, 2nd edn Prentice-Hall 1996, http://repository.umpalembang.ac.id/id/eprint/9140.

22. Zhang, Q.; Hua, Y. Corrosion inhibition of aluminium in hydrochloric acid solution by alkylimidazolium ionic liquids. Mater. Chem. Phys. 2010, 119, 57-64, https://doi.org/10.1016/j.matchemphys.2009.07.035.

23. Akinbulumo, O.A.; Odejobi, O.J.; Odekanle, E.L. Thermodynamics and adsorption study of the corrosion inhibition of mild steel by Euphorbia heterophylla L. extract in $1.5 \mathrm{M} \mathrm{HCl}$. Results in Materials 2020, 5, 100074, https://doi.org/10.1016/j.rinma.2020.100074. 
24. Abiola, O.K., Otaigbe, J.O.E.; Kio, O.J. Gossipium hirsutum L. extracts as green corrosion inhibitor for aluminium in $\mathrm{NaOH}$ solution. Corros. Sci., 2009, 51, 1879-1881, https://doi.org/10.1016/j.corsci.2009.04.016.

25. Umoren, S.A.; Ebenso, E.E. Studies of the anti-corrosive effect of Raphia hookeri exudate gum-halide mixtures for aluminium corrosion in acidic medium. Pigment and Resin Technol., 2008, 37, 173-182, https://doi.org/10.1108/03699420810871020.

26. Chaudhary, S.; Tak, R.K. Tribulus terrestris Extracts: An Eco-Friendly Corrosion Inhibitor for Mild Steel in H2SO4 Medium. Asian J. Chem. 2017, 1, 29, https://doi.org/10.14233/ajchem.2017.20702.

27. Moussaoui, N; Zerouali, D.; Bettahar N. Inhibitive effect of date extract on the corrosion of carbon steel in acidic media.J. Chil. Chem. Soc. 2016, 61, 3018-3024, http://dx.doi.org/10.4067/S071797072016000300002.

28. Kumar, C.P.; Mohana, K.N. Adsorption and thermodynamic characteristics of Plumeria rubra plant extracts on mild steel corrosion in industrial water medium. Int Res J Pure Appl Chem 2013, 2, 330-46, https://doi.org/10.9734/IRJPAC/2013/5397.

29. Abdel-Gaber, A.M.; Rahal, H.T.; Beqai, F.T. Eucalyptus leaf extract as a eco-friendly corrosion inhibitor for mild steel in sulfuric and phosphoric acid solutions. Int. J. Ind. Chem. 2020, 11, 123-132, https://doi.org/10.1007/s40090-020-00207-z.

30. Allaoui, M.; Rahim,O.; Lounes, A.; Dokkar, L.; Djabou, K. Eco-Friendly Inhibitors By Moringa Oleifera Leaves Extract On The Corrosion Of Carbon Steel In 1m Hydrochloric Acid. Mor. J. Heterocycl Chem. 2020, 19, https://doi.org/10.48369/IMIST.PRSM/jmch-v19i2.22377.

31. Sivabalan, V.; Walid, B.; Madec, Y.; Qasim, A.; Lal, B. Corrosion inhibition study on glycerol as simultaneous gas hydrate and corrosion inhibitor in gas pipelines. Malaysian J Anal Sci. 2020, 24, 62-9, https://www.researchgate.net/publication/343350462.

32. Zinad, D. S.; Jawad, Q. A.; Hussain, M.A.M.; Mahal, A.; Mohamed, L.; Al-Amiery, A.A. Adsorption, temperature and corrosion inhibition studies of a coumarin derivatives corrosion inhibitor for mild steel in acidic medium: gravimetric and theoretical investigations. Int. J. Corros. Scale Inhib. 2020, 9, 134-151, https://doi.org/10.17675/2305-6894-2020-9-1-8.

33. Buyuksagis, A.; Dİlek, M. The Use of Papaver somniferum L. Plant Extract as Corrosion Inhibitor. Prot. Met. Phys. Chem. Surf. 2019, 55, 1182-1194, https://doi.org/10.1134/S2070205119060042.

34. Iroha, N.B.; Nnanna, L.A. Electrochemical and Adsorption Study of the anticorrosion behavior of Cefepime on Pipeline steel surface in acidic Solution. J. Mater. Environ. Sci. 2019, 10, 898-908.

35. Vishwanatham, S.; Haldar, N. Corrosion inhibition of N80 steel in hydrochloric acid by phenol derivatives, Indian J. Chem. Technol., 2007, 14, 501-506.

36. Raviprabha, K.; Ramesh, S.B.; 5-(3-Pryridyl)-4H-1,2,4-triazole-3-thiol as Potential Corrosion Inhibitor for AA6061 Aluminium Alloy in 0.1 M Hydrochloric Acid Solution. Surf. Eng. Appl. Electrochem. 2019, 55, 723-733, https://doi.org/10.3103/S1068375519060103.

37. Labjar, N.; Lebrini, M.; Bentiss, F.; Chihib, N.E.; El Hajjaji, S.; Jama, C. Corrosion inhibition of carbon steel and antibacterial properties of aminotris-(methylenephosphonic) acid. Mater. Chem. Phys. 2010, 119, 330336, https://doi.org/10.1016/j.matchemphys.2009.09.006.

38. Gomes, M.P.; Costa, I.; Pébère, N.; Rossi, J.L.; Tribollet, B.; Vivier, V. On the corrosion mechanism of Mg investigated by electrochemical impedance spectroscopy. Electrochim. Acta 2019, 306, 61-70, https://doi.org/10.1016/j.electacta.2019.03.080.

39. Noor, E.A. Evaluation of inhibitive action of some quaternary N-heterocyclic compounds on the corrosion of $\mathrm{Al}-\mathrm{Cu}$ alloy in hydrochloric acid. Mater. Chem. Phys. 2009, 114, 533-541, https://doi.org/10.1016/j.matchemphys.2008.09.065.

40. Espinoza-Vázquez, A.; Rodríguez-Gómez, F.J.; Martínez-Cruz, I.K.; Ángeles-Beltrán, D.; Negrón-Silva, G.E.; Palomar-Pardavé, M.; Romero, L.L.; Pérez-Martínez, D.; Navarrete-López, A.M. Adsorption and corrosion inhibition behaviour of new theophylline-triazole-based derivatives for steel in acidic medium. $R$. Soc. Open Sci. 2019, 27, 6, 181738, https://doi.org/10.1098/rsos.181738.

41. Fouda, A.S.; El-Desoky, H.S.; Abdel-Galeil, M.A.; Mansour, D. Niclosamide and dichlorphenamide: new and effective corrosion inhibitors for carbon steel in $1 \mathrm{M} \mathrm{HCl}$ solution. SN Appl. Sci. 2021, 3, 1-20, https://doi.org/10.1007/s42452-021-04155-w.

42. Chraka, A.; Raissouni, I.; Seddik, N.B.; Khayar, S.; Mansour, A.I.; Tazi, S.; Chaouket, F.; Bouchta, D. Identification of Potential Green Inhibitors Extracted from Thymbra capitata (L.) Cav. for the Corrosion of Brass in 3\% $\mathrm{NaCl}$ Solution: Experimental, SEM-EDX Analysis, DFT Computation and Monte Carlo Simulation Studies. J Bio- Tribo-Corros. 2020, 6, 1-19, https://doi.org/10.1007/s40735-020-00377-4.

43. Farghaly, O.A.; Al-Shafey, H.I.; Abd El-Hameed, R.S. Corrosion of mild steel in NaCl solutions and effect of recycled plastic waste inhibitors. Res Rev Electrochem. 2012, 3, 41-49. 